\title{
A rare cause of hypercalcemia: Questions
}

\author{
Chia Wei Teoh • Irwin Gill • Rania Haydar • \\ Melanie Cotter • Deirdre Devaney • Niamh Marie Dolan • \\ Michael Riordan • Mary Waldron • Atif Awan
}

Received: 17 October 2013 / Revised: 12 November 2013 / Accepted: 12 November 2013 / Published online: 3 January 2014

(C) IPNA 2013

Keywords Sarcoidosis $\cdot$ Hypercalcemia $\cdot$ Paediatric sarcoidosis $\cdot$ Lymphadenopathy $\cdot$ Non-caseating granuloma

\section{Case summary}

A previously well 12-year-old boy presented with a 1month history of polydipsia, polyuria, and lethargy. Over that period, he had been drinking at least 31 of water daily, reported feeling thirsty, and needed to pass urine approximately every $30 \mathrm{~min}$. His parents also reported that he had weight loss over the previous month with reduced appetite secondary to nausea. Of note, he had a long-standing history of drinking approximately 11 of cow's milk daily. He had no recent acute illnesses or fevers and reported no pain, discomfort, or respiratory distress. He had been treated with azathioprine for 3 years in the past for intractable eczema. His blood glucose level checked by his general practitioner was normal.

The answers to these questions can be found at http://dx.doi.org/10.1007/ s00467-013-2707-1

C. W. Teoh $(\bowtie) \cdot$ I. Gill $\cdot$ R. Haydar $•$ N. M. Dolan • M. Riordan • M. Waldron - A. Awan

The Department of Paediatric Nephrology \& Transplantation, The Children's University Hospital, Temple Street, Dublin 1, Ireland

e-mail: cwteoh88@hotmail.com

\section{Cotter}

The Department of Haematology, The Children's University

Hospital, Temple Street, Dublin 1, Ireland

\section{Devaney}

The Department of Pathology, The Children's University Hospital, Temple Street, Dublin 1, Ireland
Physical examination revealed significant bilateral inguinal lymphadenopathy and a 2-cm palpable liver edge. There were patches of dry skin attributed to previously diagnosed eczema. His cardiovascular, respiratory, neurological, ENT, and musculoskeletal examinations were otherwise unremarkable. There was an evident BCG scar. Vital signs were within normal limits.

Laboratory investigations revealed acute renal impairment, hypercalcemia, and a mild transaminitis: urea $15.2 \mathrm{mmol} / \mathrm{l}$, creatinine $149 \mathrm{mmol} / \mathrm{l}$, serum calcium $3.38 \mathrm{mmol} / \mathrm{l}$, ionized calcium $1.78 \mathrm{mmol} / 1$, serum phosphate $1.42 \mathrm{mmol} / \mathrm{l}$, sodium $139 \mathrm{mmol} / \mathrm{l}$, potassium $3.7 \mathrm{mmol} / \mathrm{l}$, AST $76 \mathrm{U} / \mathrm{l}$, ALT $114 \mathrm{U} / \mathrm{l}$, and lactate dehydrogenase $416 \mathrm{U} / \mathrm{l}$. Serum intact parathyroid hormone levels were suppressed at $<6 \mathrm{ng} / \mathrm{l}$. Serum $25(\mathrm{OH})$-cholecalciferol level was reduced at $38 \mathrm{nmol} / \mathrm{l}$. Urinalysis revealed significant hypercalciuria (calcium/ creatinine ratio of 2.91). Full blood count measurements were within normal limits, while blood film revealed only occasional atypical lymphocytes and monocytes. An abdominal ultrasound revealed bilateral hyperechogenic kidneys, which were otherwise unremarkable; and mild hepatosplenomegaly with bulky inguinal lymph nodes bilaterally with speckled hyperechogenicity. A chest radiograph revealed clear lung fields, normal-sized cardiac silhouette with no evidence of a widened mediastinum.

\section{Questions}

1) What differential diagnoses would you consider to be possible causes of the hypercalcemia?

2) What is the most likely cause of his presentation?

3) What further diagnostic investigations would you consider?

4) How would you treat hypercalcaemia? 